\title{
Influence of Combining Real-time and Fixed Tariffs in the Demand Response Aggregation and Remuneration Scheems Definition
}

\author{
Cátia Silva, Pedro Faria and Zita Vale \\ Polytechnic of Porto \\ Porto, Portugal \\ cvcds@isep.ipp.pt;pnf@isep.ipp.pt;zav@isep.ipp.pt
}

\begin{abstract}
The electric sector revolution towards Smart Grids, requires new market models. The authors propose a business model that allows the virtual power player to manage the small resources like distributed generation units, consumers belonging to demand response programs, and prosumers. Grouping these resources and remunerating them according to the maximum tariff of the group that was allocated is proposed. The purpose of this paper is to understand whether the tariff associated with each resource influences or not the formation of groups when applying the clustering method. Three case studies were carried out: aggregation only with the potential of each resource, power and the fixed tariff and, finally, taking into account a tariff that changes according to the period of the day.
\end{abstract}

Index Terms-- Aggregation, Business Models, K-means, Remuneration, Tariffs.

\section{INTRODUCTION}

The liberalisation of the electricity market, the concept of smart grids, the promotion of renewable energy sources, the empowerment of consumers are only some examples of the reasons why it is justifiable to change the business models of the electric sector, [1]. The introduction of competitiveness has revolutioned the way that the market is managed. Bidirectional communication in the network allows the consumer to make part of the market in a direct way [2], [3]. The creation of a new type of consumer, the so-called Prosumers, who manage to produce locally and satisfy his consumption at certain times, will influence the way the network is managed. Only the fact that Prosumers can sell part of their production to the network or even their community requires a radical change in relation to current models.

Having the consumer access to electricity price information in real time and can change its consumption as the need, arises the need to create a new tariff, [4]. Thus, it is

The present work was done and funded in the scope of the following projects: CONTEST Project (P2020 - 23575), and UID/EEA/00760/2013 funded by FEDER Funds through COMPETE program and by National Funds through FCT. anticipated that in the future a method for formation this new tariff is used. This may included a variable that takes into account a price that changes according to the period of the day - an indexed tariff. In other words, in an indexed tariff, the value of the energy tariff is indexed to the daily market price of electricity, which has an period variation, [5]. Thus, in this type of tariff, the consumer sees reflected in his invoice the variations of the electricity price, with a commercial margin (spread) by the provision of the energy supply service, defined by the trader.

The author proposes a business model that includes all these new concepts. The proposed method addresses a solution that aggregates new resources - distributed production units, consumers who belong to demand response and prosumers programs, and manages them in an optimal way. This is the development of previous works, [6], and it results in a model that proposes the remuneration of these small resources that participate in conjunction with the aggregator for effective community management. The remuneration is made taking into account the generation of groups, through a clustering method. The objective is to provide the aggregator of a significant amount of energy to participate in the market and to remunerate fairly the associates. Each group will have an associated tariff. This paper will try to understand the influence of the tariff associated with each resource in the creation of the groups and how this new tariff behaves in this situation.

Section I presents the introduction to the subject and the main purpose of the paper. In section II, all phases of the proposed model are discussed in detail. In section III, the case study is presented and the way the results were treated. These results will be analysed in section IV. Finally, section V presents the main conclusions drawn from the work carried out. 


\section{AGGREGATION, REMUNERATION, AND TARIFFS COMPARISON}

In this section it is detailed all phases of the proposed methodology to assist the aggregator in the management of the community of consumers, producers, and prosumers associated to him. Figure 1 presents the four phases of the proposed methodology.
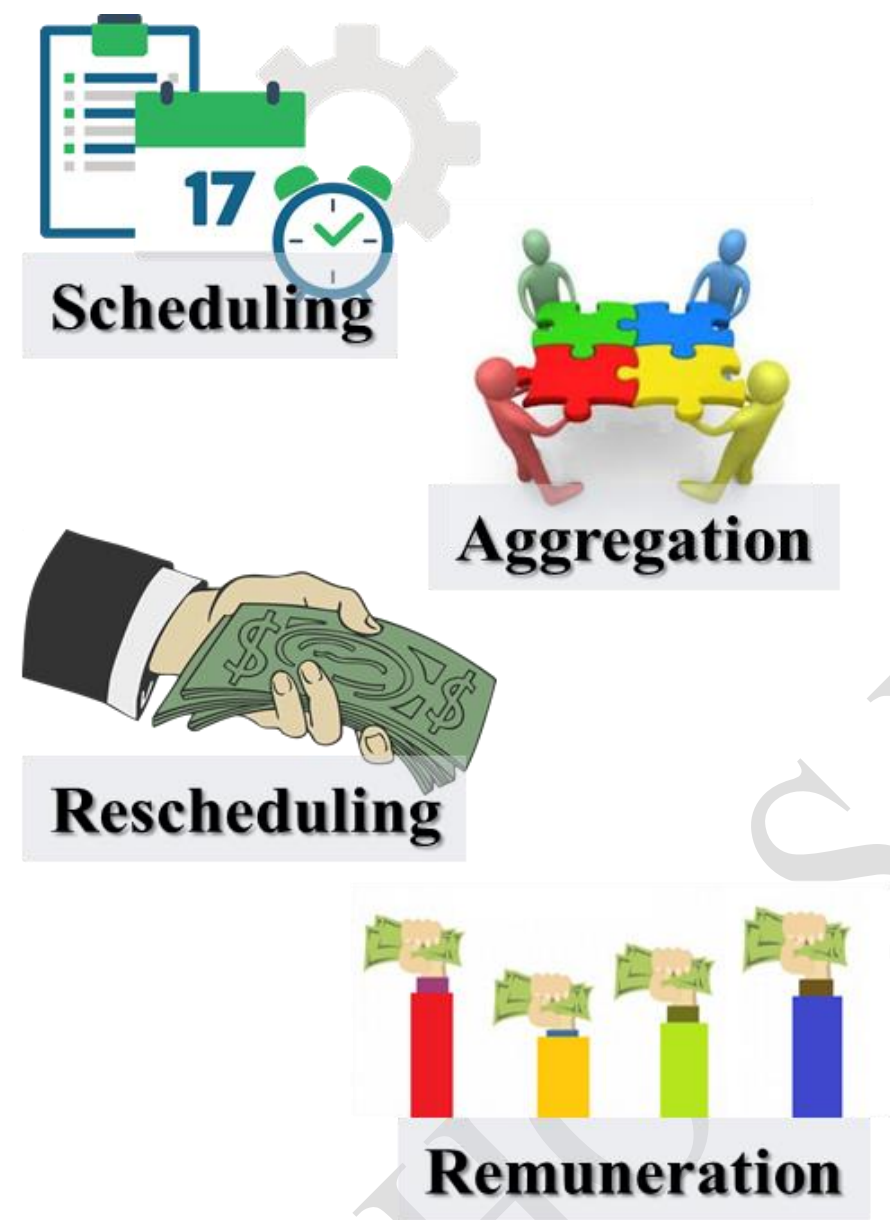

Figure 1. Proposed methodology

Figure 1 represents a model proposed in [6] and demonstrating the role of the aggregator in the network infrastructure and the market in the electricity sector.

In the first phase we take into account the resources of a certain community associated with a virtual power player (VPP) for optimal scheduling - these being Distributed Generation (DG) units, consumers participating in Demand responds (DR) and suppliers programs. The latter, the suppliers, will be used if, in a certain situation, the remaining resources cannot satisfy the demand. In other words, according to several input variables related to these small resources, an optimization will be performed to perceive the optimum contribution of each of them for a given period. The profiles used as inputs may include, for example, the possibilities of direct control of the load or even the existence of production, both heat and electricity. The objective function of this problem is to minimize the operating costs from the point of view of the VPP and will also have the objective to remunerate fairly all the resources that are aggregated and actively participate in the management of Community. In this way, price and operation constraints are considered in this optimization as well as operational constraints imposed by the VPP to achieve its objectives. The MATLAB software potentials were used through the toolbox, TOMLAB.

In relation to the second phase, it aims to create resource groups to facilitate their remuneration in the last phase of the model. Thus, the definition of these groups is made taking into account the results obtained in the optimization of the previous phase - power scheduled for each of the resources. In this article, as the objective will be to understand the influence of tariffs on the creation of these groups, it was also added the tariff that each resource would be remunerated in the case of non-creation of these groups. This rate consists of the sum of a fixed tariff - tariff established by the energy supplier, and an indexed tariff - tariff that varies according to the market price and has hourly variation.

It is recalled that this aggregation phase is advantageous for both sides. By grouping these small resources, the VPP will have a considerable amount of energy to enter the market. At the same time, it will allow entry into the negotiation of these small consumers and producers since, to date, they did so indirectly. For this aggregation, only one clustering method was used, namely, k-means, and several $\mathrm{k}$ clusters were compared. This method is one of the most famous of unsupervised machine learning when it comes to partitioning. In 1979, Hartigan-Wong defined one of the possible variations of this method. The total variation within a cluster is then taken as the sum of the squares of Euclidean distance between a point and the center of the cluster, and then assigns the point to the nearest cluster, [7]. This study was carried out using software R.

With regard to the rescheduling phase, this third stage picks up the previously formed groups and creates a single remuneration fee for a given group. In the case of a study presented in this paper, the maximum rate of each group was considered.

The last phase, the remuneration of the groups, the resources will be rewarded by continued collaboration with the aggregator for effective management of the operation. This phase serves as motivation and as a promotion for new candidates for community aggregation. The maximum will be, through the cooperation of all resources, to reach a point where network management can flow in an optimum way. With the tariff generated for each group, each resource will be paid according to the amount of energy they contributed. And that will be paid only in the end of the schedule.

\section{CASE STUDY}

Through a real network of Portuguese distribution, which consists of a certain of 548 distributed production units and 20 310 consumers that may belong to Demand Response programs, the application of the proposed methodology is demonstrated. 
It was considered that these Consumers may belong to two types of programs: Price-based and incentive-based. In The first case, consumers that can change their consumption patterns with responses to real-time electricity price changes (RTP). On the other hand, through incentive-based programs, consumers are paid at a fixed price $\mathrm{kW}$ of reduced load. Pricebased (RTP) and Incentive based programs, namely, Reduce and Cut, were applied in this study to different types of consumers: Domestic (DM), Small Commerce (SM), Medium Commerce (MC), Large Commerce (LC) and industrial (ID). TABLE I presents the characterization of DR consumers and the possibilities of participation in the DR programs.

TABLE I. DEMAND RESPONSE CONSUMERS CHARACTERIZATION

\begin{tabular}{|c|c|c|c|c|}
\hline Designation & Reduce & Cut & RTP & $\begin{array}{c}\text { Initial Price } \\
\text { (m.u./kWh) }\end{array}$ \\
\hline Domestic (DM) & $\bullet$ & & & 0.12 \\
\hline Small commerce (SM) & $\bullet$ & & & 0.18 \\
\hline Medium commerce (MC) & & $\bullet$ & & 0.19 \\
\hline Large commerce (LC) & & $\bullet$ & & 0.19 \\
\hline Industrial (ID) & & & $\bullet$ & 0.15 \\
\hline Total No of DR & 19996 & 167 & 147 & 20310 \\
\hline Total Capacity (kWh) & 8676 & 1106 & 11571 & 21354.36 \\
\hline
\end{tabular}

With regard to the other type of resource presented, DG, several types were considered in this study, namely wind, biomass, small hydro, co-generation, photovoltaic, fuel-cell and waste-to-energy. TABLE II presents the detailed information for each DG, showing the unit number by type, the unit operating price in m.u./kWh and the total available capacity.

TABLE II. DISTRIBUTED GENERATION CHARACTERIZATION

\begin{tabular}{|c|c|c|c|}
\hline Designation & $\mathbf{N}^{\mathbf{0}}$ of units & $\begin{array}{c}\text { Capacity } \\
(\mathbf{k W h})\end{array}$ & $\begin{array}{c}\text { Price } \\
(\mathbf{m . u .} / \mathbf{k W h})\end{array}$ \\
\hline Wind & 254 & 5866.09 & 0.071 \\
\hline Co-generation & 16 & 6910.10 & 0.00106 \\
\hline Waste-to-energy & 7 & 53.10 & 0.056 \\
\hline Photovoltaic & 208 & 7061.28 & 0.150 \\
\hline Biomass & 25 & 2826.58 & 0.086 \\
\hline Fuel cell & 13 & 2457.60 & 0.098 \\
\hline Small hydro & 25 & 214.05 & 0.042 \\
\hline Total DG & 548 & \multicolumn{2}{|c|}{$25388.79 \mathrm{kWh}$} \\
\hline
\end{tabular}

In the optimization phase, 2592 scenarios were created to study this problem. In this paper only one will be studied, being selected as example scenario the 1674. After the optimization phase is complete, a clustering method is used to aggregate the different resources. In this article, several $\mathrm{k}$ clusters were compared to understand which would be most appropriate for the situation in question.

The main objective of this paper will be to understand the influence that the remuneration tariff will have on the formation of the groups when applying the clustering method.
Thus, the problem was addressed in three ways in order to compare several cases: to group the resources without including the fixed tariff, including the fixed tariff and at the end including the fixed tariff and the indexed tariff, varying the weights of each one in the formation of the final tariff.

It was considered that the final tariff for remuneration of each group, presented along the following section in several cases, will be the maximum tariff of that group.

\section{RESULTS}

Section IV presents the results of the application of the model proposed in section II taking into account the case study of the previous section. In a first phase and in order to serve as a base for the following studies, DG resources were added, as was done in previous studies, for example [8] - only with the results of the optimization - power staged to the resource in a given period.

Figure 2 shows the result of applying kmeans to the sample used for $\mathrm{k}=3$ to $\mathrm{k}=6$.

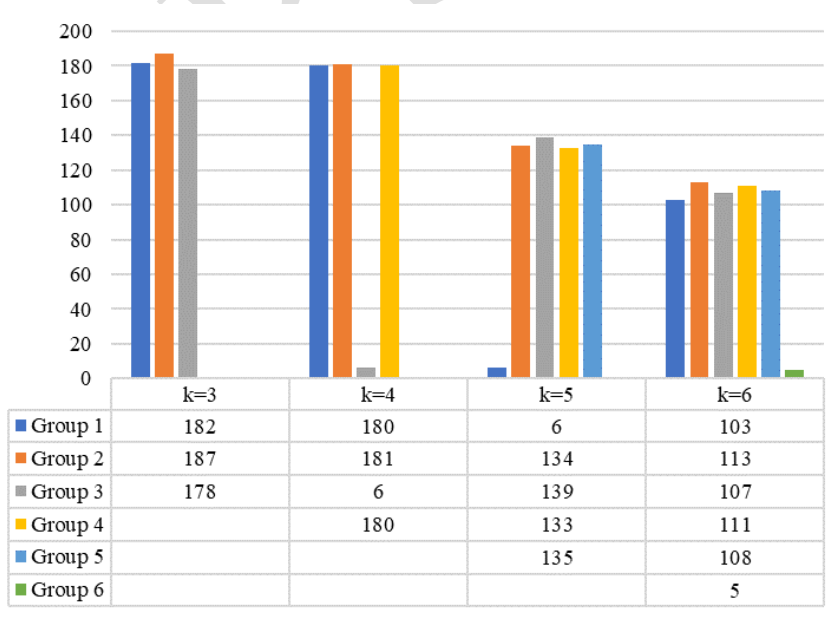

Figure 2. K-means Results - Only Results from Otimization

The results presented show, in the first instance, that the sample presented contains a small amount of points, six in $\mathrm{k}=4$ and $\mathrm{k}=5$ and five in $\mathrm{k}=6$, which departs from the remaining ones, showing that they are very different of the remaining ones.

TABLE III presents the results for the maximum tariffs of each group. It is recalled that in this first phase, these values did not serve as input for the clustering method used.

TABLE III. MAXIMUM TARIFFS FOR EACH GROUP - ONLY RESULTS FROM OTIMIZATION

\begin{tabular}{|l|c|c|c|c|}
\hline & $\mathrm{k}=3$ & $\mathrm{k}=4$ & $\mathrm{k}=5$ & $\mathrm{k}=6$ \\
\hline Group 1 & 0.176313418 & 0.176313418 & 0.174443485 & 0.17584079 \\
\hline Group 2 & 0.176086198 & 0.176290389 & 0.17615558 & 0.17615558 \\
\hline Group 3 & 0.176290389 & 0.174443485 & 0.176218572 & 0.175418718 \\
\hline Group 4 & & 0.176086198 & 0.176086198 & 0.176313418 \\
\hline Group 5 & & & 0.176313418 & 0.176086198 \\
\hline Group 6 & & & & 0.174443485 \\
\hline
\end{tabular}


Analyzing TABLE III, it is concluded that differences between groups for these tariffs are only notable from the hundredth. In $\mathrm{k}=3$, the rates are very similar between groups. In $\mathrm{k}=4$, the tariffs are the same as previously modifying only in Group 3 where there is a change in the milliseconds. In $\mathrm{k}=$ 6 There is a greater variety of fares. Figure 3 now presents the results for the aggregation of resources taking into account the scheduling power and the fixed tariff of each of them.

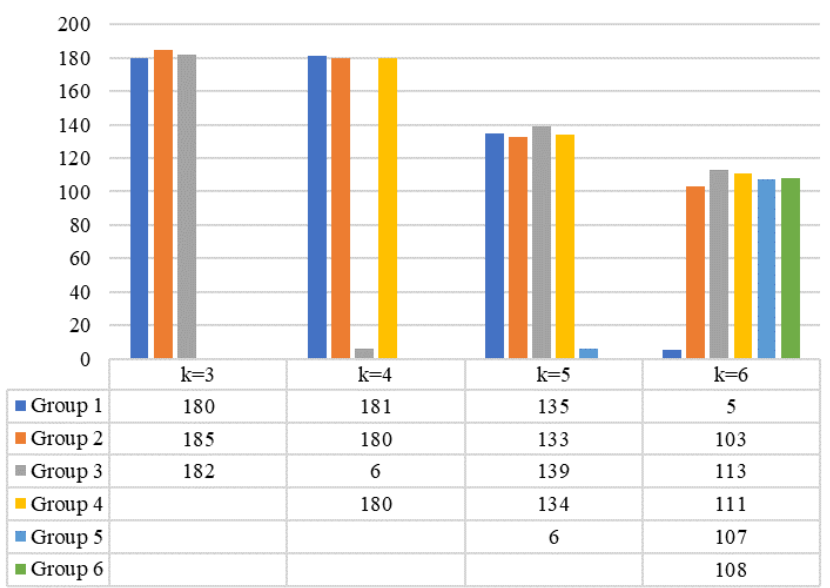

Figure 3.K-means Results - Results from Otimization and Fix Tariff

Comparing Figure 2 and 3, although the method has been assigned to different groups, the number of elements is identical in all cases. Similarly, TABLE IV shows the maximum fare resulting from each group for new aggregation.

TABLE IV. DEMAND RESPONSE CONSUMERS CHARACTERIZATION

\begin{tabular}{|l|c|c|l|l|}
\hline & $\mathrm{k}=3$ & $\mathrm{k}=4$ & $\mathrm{k}=5$ & $\mathrm{k}=6$ \\
\hline Group 1 & 0.176313418 & 0.176290389 & 0.17615558 & 0.174443485 \\
\hline Group 2 & 0.176086198 & 0.176313418 & 0.176313418 & 0.17584079 \\
\hline Group 3 & 0.176290389 & 0.174443485 & 0.176218572 & 0.17615558 \\
\hline Group 4 & & 0.176086198 & 0.176086198 & 0.176313418 \\
\hline Group 5 & & & 0.174443485 & 0.175418718 \\
\hline Group 6 & & & & 0.176086198 \\
\hline
\end{tabular}

How can you check and as already mentioned, although the composition of a group in question is different, when it comes to the number of elements, the results are identical, no much influence of the tariff for these two cases.

From this moment on, the approach becomes different. The remuneration tariff consists of a fixed part and another variable - the indexed tariff. This tariff was withdrawn from the Mercado Ibérico de Eletricidade (MIBEL) on October 22, 2018 in which the electricity price would be 63.19 m.u./MWh. Five study cases were created for this situation. First, the weight of each of the variables is equal, i.e. $50 \%$ for each of the tariff that forms the final tariff. The remaining ones were created by increasing the percentage of the fixed tariff by $10 \%$, thereby decreasing the same value in the indexed tariff. Thus, Figure 4 shows the result for $\mathrm{k}=3$ for all study cases. When analyzing the figure, the composition of the groups is similar. It can be emphasized the case of 80/20 in which group 3 is formed by the same six resources that were highlighted in the previous cases.

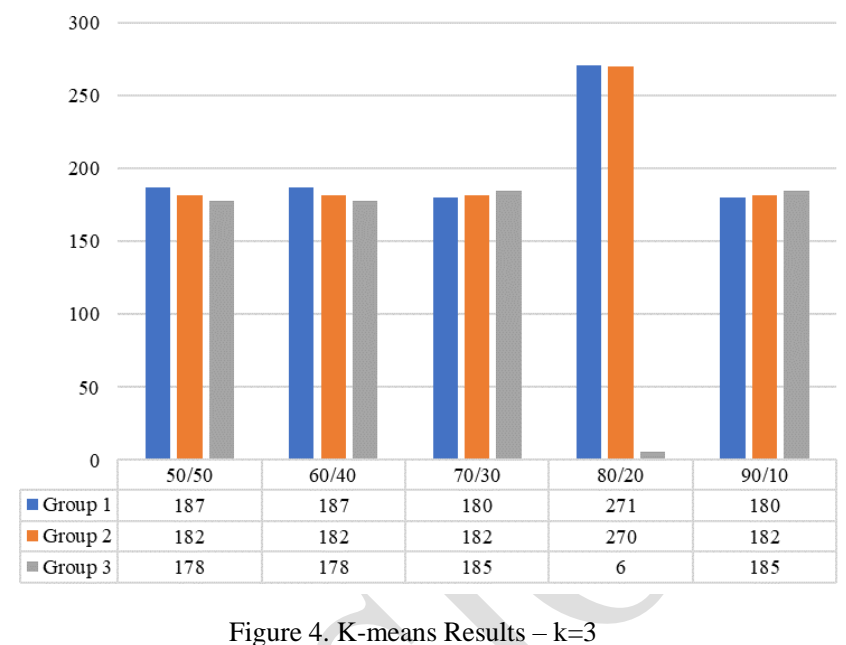

It is also evident that the higher the percentage of the fixed fare, the closer it is to the values of the groups presented in Figures 2 and 3. Figure 5 shows the results for $k=4$.

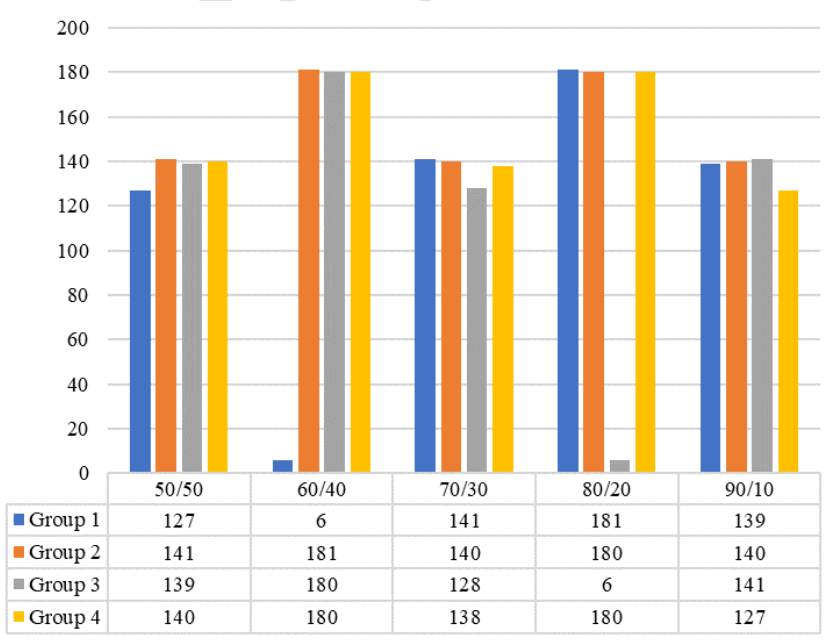

Figure 5. K-means Results $-\mathrm{k}=4$

The results for $\mathrm{k}=4$ and presented in Figure 5 show that only two of the cases, $60 / 40$ and $80 / 20$, create a group for the same six resources previously evidenced. In other cases, they continue to insert them with the remaining elements.

Figure 6 shows the results for $\mathrm{k}=5$. In $\mathrm{k}=5$, it is already possible to verify in all groups that somehow can identify the six resources as a single group. Figure 7 shows the results for $\mathrm{k}=6$. So far, it has been recurrent that the case 80/20 differs from the remainder. In $k=6$, this case also divided the said six resources into two distinct groups, not happening in any other situation.

When comparing all figures referring to the results of the clustering method, it is possible to verify the difference in the composition of the groups in all situations. Although in the beginning of this case study (fixed tariff and indexed tariff), the composition of the groups, mostly being identical, as the number of $\mathrm{k}$ increases, the composition of the groups tends to be more different from the cases without and with fixed rate presented in first place. 


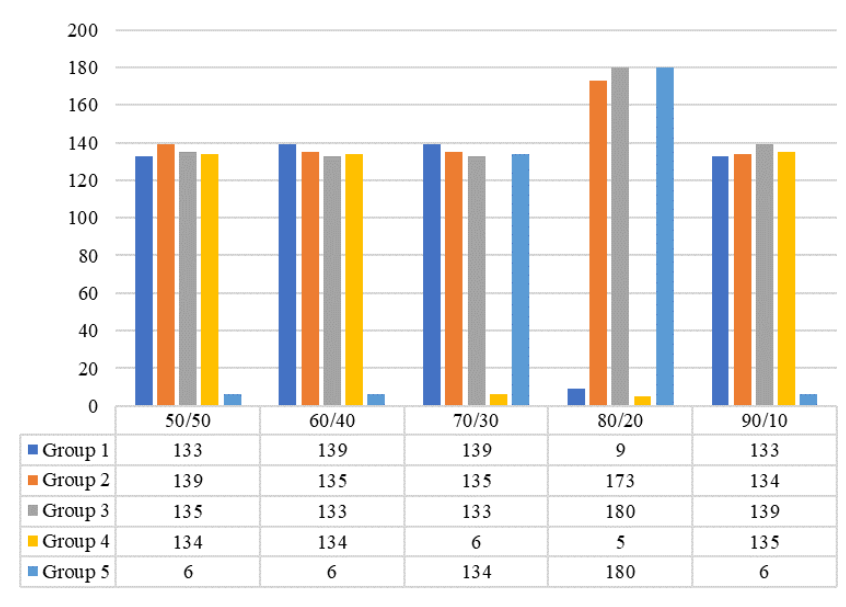

Figure 6. K-means Results $-\mathrm{k}=5$

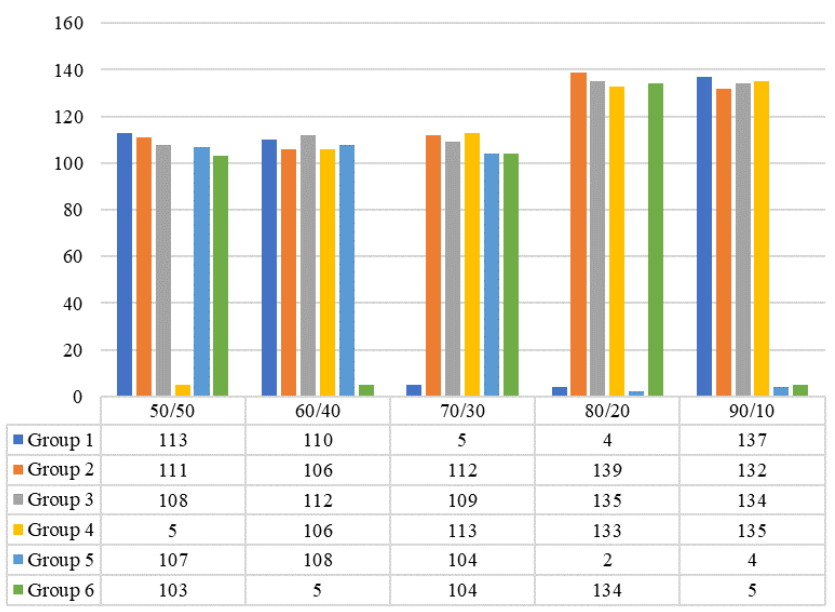

Figure 7. K-means Results $-\mathrm{k}=6$

Now, in TABLE V to IX, the maximum tariffs resulting from the division of the groups are presented. In this case, the different k clusters will be compared for each case of study concerning the different percentages attributed to the fixed tariff and the indexed tariff.

TABLE V. MAXIMUM TARIFF FOR EACH GROUP - CASE 50/50

\begin{tabular}{|l|l|l|l|l|}
\hline & $50 / 50$ & $\mathrm{k}=4$ & $\mathrm{k}=5$ & $\mathrm{k}=6$ \\
\hline & $\mathrm{k}=3$ & $\mathrm{k}=4$ & 0.119673 \\
\hline Group 1 & 0.119638 & 0.119638 & 0.119638 & 0.119752 \\
\hline Group 2 & 0.119752 & 0.119704 & 0.119704 & 0.119638 \\
\hline Group 3 & 0.119740 & 0.119673 & 0.119752 & 0.118817 \\
\hline Group 4 & & 0.119752 & 0.119673 & 0.119304 \\
\hline Group 5 & & & 0.118817 & 0.119515 \\
\hline Group 6 & & & & \\
\hline
\end{tabular}

TABLE VI. MAXIMUM TARIFF FOR EACH GROUP - CASE 60/40

\begin{tabular}{|c|c|c|c|c|}
\hline 7 & $60 / 40$ & & & \\
\hline & $\mathrm{k}=3$ & $\mathrm{k}=4$ & $\mathrm{k}=5$ & $\mathrm{k}=6$ \\
\hline Group 1 & 0,130928 & 0,129942 & 0,131007 & 0,130999 \\
\hline Group 2 & 0,131064 & 0,13105 & 0,131064 & 0,130527 \\
\hline Group 3 & 0,13105 & 0,131064 & 0,130928 & 0,130969 \\
\hline Group 4 & & 0,130928 & 0,130969 & 0,130928 \\
\hline Group 5 & & & 0,129942 & 0,131064 \\
\hline Group 6 & & & & 0,129942 \\
\hline
\end{tabular}

TABLE VII. MAXIMUM TARIFF FOR EACH GROUP - CASE 70/30

\begin{tabular}{|l|l|l|l|l|}
\hline & $70 / 30$ & $\mathrm{k}=5$ & $\mathrm{k}=6$ \\
\hline & $\mathrm{k}=3$ & $\mathrm{k}=4$ & $\mathrm{k}=5$ \\
\hline Group 1 & 0.142376 & 0.14231 & 0.14231 & 0.141067 \\
\hline Group 2 & 0.14236 & 0.142217 & 0.142266 & 0.142266 \\
\hline Group 3 & 0.142217 & 0.142376 & 0.142376 & 0.142376 \\
\hline Group 4 & & 0.14236 & 0.141067 & 0.142301 \\
\hline Group 5 & & & 0.142217 & 0.142217 \\
\hline Group 6 & & & & 0.14175 \\
\hline
\end{tabular}

TABLE VIII. MAXIMUM TARIFF FOR EACH GROUP - CASE 80/20

\begin{tabular}{|l|l|l|l|l|}
\hline & \multicolumn{5}{l}{} \\
\hline & $\mathrm{k}=3$ & $\mathrm{k}=4$ & $\mathrm{k}=5$ & $\mathrm{k}=6$ \\
\hline Group 1 & 0.153562 & 0.15367 & 0.153689 & 0.152193 \\
\hline Group 2 & 0.153689 & 0.153507 & 0.15367 & 0.153613 \\
\hline Group 3 & 0.152193 & 0.152193 & 0.153562 & 0.153689 \\
\hline Group 4 & & 0.153689 & 0.152193 & 0.153507 \\
\hline Group 5 & & & 0.153507 & 0.093330 \\
\hline Group 6 & & & & 0.153562 \\
\hline
\end{tabular}

TABLE IX. MAXIMUM TARIFF FOR EACH GROUP - CASE 90/10

\begin{tabular}{|c|c|c|c|c|}
\hline & $90 / 10$ & \multicolumn{3}{|c|}{ 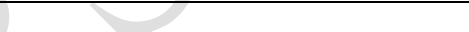 } \\
\hline & $\mathrm{k}=3$ & $\mathrm{k}=4$ & $\mathrm{k}=5$ & $\mathrm{k}=6$ \\
\hline Group 1 & 0.164797 & 0.164859 & 0.165001 & 0.164916 \\
\hline Group 2 & 0.16498 & 0.165001 & 0.164797 & 0.164797 \\
\hline Group 3 & 0.165001 & 0.164916 & 0.164916 & 0.164859 \\
\hline Group 4 & 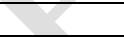 & 0.164797 & 0.164859 & 0.16498 \\
\hline Group 5 & 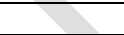 & & 0.163318 & 0.165001 \\
\hline Group 6 & & & & 0.163318 \\
\hline
\end{tabular}

When analyzing this set of tables, it is visible that these tariffs have a lower value than in cases where the fixed rate existed, highlighting this advantage in relation to these cases. Another of the conclusions is that, the more groups are created, the more diversity of tariffs exists since the composition of the groups can and result in different maximum tariffs.

TABLE $X$ presents the totals to be remunerate in each $\mathrm{k}$ cluster according to the total contribution of all groups to the tariff of each.

TABLE X. FINAL REMUNERATION FOR EACH CASE

\begin{tabular}{|l|l|l|l|l|l|}
\hline & $50 / 50$ & $60 / 40$ & $70 / 30$ & $80 / 20$ & $90 / 10$ \\
\hline $\mathrm{k}=3$ & 1796.671 & 1966.332 & 2135.951 & 2295.057 & 2475.26 \\
\hline $\mathrm{k}=4$ & 1796.353 & 1966.195 & 2135.827 & 2305.47 & 2474.741 \\
\hline $\mathrm{k}=5$ & 1796.311 & 1965.899 & 2135.485 & 2304.879 & 2474.661 \\
\hline $\mathrm{k}=6$ & 1794.123 & 1963.891 & 2133.124 & 2303.705 & 2474.635 \\
\hline
\end{tabular}

In $\mathrm{k}=6$, it is where the minimum remuneration values are obtained excepting the case of $80 / 20$ that the minimum value was reached in $\mathrm{k}=3$.

\section{CONCLUSIONS}

The market in the energy sector lacks a model that includes the concepts introduced by Smart Grids. The bidirectionality, the possibility of production by consumers, the competitiveness of the market and other factors that increase the difficulty of managing the operation of the network. Thus, the authors propose a solution that aims to aggregate small resources of a community into groups and compensate them according to their contribution. The tariffs to 
which they are remunerated may influence the way in which these groups are created. This was the objective of this paper: to test how this rate can affect this phase of the proposed business model. It was perceived that the greater the division of the database, the greater diversity in tariffs and that the influence on the creation of the groups is not so impactful.

\section{REFERENCES}

[1] H. Yves and S. Teufel, "Prosumer communities: Electricity as an interpersonal construct," 2016 Int. Conf. Smart Grid Clean Energy Technol. ICSGCE 2016, pp. 89-94, 2017.

[2] Y. Yan, Y. Qian, H. Sharif, and D. Tipper, "A survey on smart grid communication infrastructures: Motivations, requirements and challenges," IEEE Commun. Surv. Tutorials, vol. 15, no. 1, pp. 5-20, 2013.

[3] P. Siano, "Demand response and smart grids - A survey," Renew. Sustain. Energy Rev., vol. 30, pp. 461-478, 2014.
[4] P. Palensky and D. Dietrich, "Demand side management: Demand response, intelligent energy systems, and smart loads," IEEE Trans. Ind. Informatics, vol. 7, no. 3, pp. 381-388, 2011.

[5] H. Zhang, F. Zhao, K. Fang, and J. W. Sutherland, "Energy-conscious flow shop scheduling under timeof-use electricity tariffs," CIRP Ann. - Manuf. Technol., vol. 63, no. 1, pp. 37-40, 2014.

[6] P. Faria, J. Spínola, and Z. Vale, "Aggregation and Remuneration of Electricity Consumers and Producers for the Definition of Demand-Response Programs," IEEE Trans. Ind. Informatics, vol. 12, no. 3, pp. 952-961, 2016.

[7] L. Morissette and S. Chartier, "The k-means clustering technique: General considerations and implementation in Mathematica," Tutor. Quant. Methods Psychol., vol. 9, no. 1, pp. 15-24, 2013.

[8] C. Silva, P. Faria, and Z. Vale, "Discussing Different Clustering Methods for the Aggregation of Demand Response and Distributed Generation," 2018. 